\title{
A Playful Approach to Fostering Motivation in a Distance Education Computer Programming Course: Behaviour Change and Student Perceptions
}

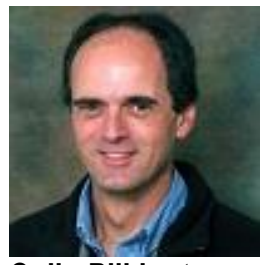

Colin Pilkington

School of Computing, University of South Africa

\begin{abstract}
The central role of motivation to learn in distance education has been noted, and gamification has been proposed as one approach to promote student motivation. This study explores promoting motivation in a distance education, third-year computer programming course via a gamified approach to improve coursework participation and student experience. Motivation was examined from a Self-Determination Theory (SDT) perspective, as gamified approaches often rely on external motivation and the explicit use of competition to engender internal motivation leading to desired behaviours. The results of using gamification in education are mixed, and its use is controversial. Two cycles of action research on the introduction of eight playful elements are reported on, and data relating to student engagement with the course and a student questionnaire was gathered. There was little evidence that the intervention led to behaviour change or improved scores; however, students responded very positively to the intervention, although some negative themes emerged. The extent to which the playful approach supported the basic psychological needs of SDT is discussed and the intervention's results critically considered, including whether the effort involved in such an approach was worth it. It was concluded that such playful approaches might have positive motivational effects.
\end{abstract}

Keywords: motivation, self-determination theory, guided didactic conversation, gamification, distance learning 


\section{Introduction}

The central role of motivation to learn in distance education has been identified, and it is recognised as a good predictor of student retention and success. Specifically, a motivated student will spend time and effort on something that motivates him/her (Buckley \& Doyle, 2014; Chen \& Jang, 2010; Hartnett, St. George, \& Dron, 2011; Simpson, 2008, 2012). Distance learners are also particularly vulnerable to the loss of motivation due to various reasons: feelings of isolation and limited face-to-face interaction, lower levels of engagement, a sense of lack of making progress, and time pressures brought on by mixing studies with family and work (Abu-Dawood, 2016; Butgereit, 2015; Keller, 1999; Simpson, 2012). Motivation may also be affected by the reason a student is taking online, distance studies (Chen \& Jang, 2010): out of interest or self-fulfilment, aiming for a better salary, or simply because there are limited opportunities in more traditional, face-to-face learning institutions where learning at a distance is not the student's first choice (Simonson, Smaldino, Albright, \& Zvacek, 2012).

Gamification may be seen as the explicit use of competition to promote student motivation (Buckley \& Doyle, 2014), and the use of the motivational power of games does not seem unreasonable (Sailer, Hense, Mayr, \& Mandl, 2017). There is increased interest in using gamified approaches in education as a means to hook, and hold, student attention and interest, as well as there being evidence that these influence student behaviour (Buckley \& Doyle, 2014). In a sense, education is already gamified: students earn marks for completing tasks, which are translated into grades at the end of a year, which then allow a student who has performed well to level-up to the next grade or year (Buckley \& Doyle, 2014).

It has been pointed out that programming courses are considered difficult, have a negative image among students, and usually rely on practice to become comfortable with their abstract and complex concepts - all factors that mitigate against building motivation (Butler \& Ahmed, 2016; Fotaris, Mastoras, Leinfellner, \& Rosunally, 2016; Pineda-Corcho \& Moreno-Cadavid, 2017). This study investigated whether a playful approach to a distance education programming course could motivate students to increase their participation in the work of the course. Furthermore, it considered how students experienced this approach. Specifically, the following research questions were asked:

- To what extent would a playful, gamified approach change student behaviour and lead to increased levels of participation in the work of the course? Would it lead to improved levels of achievement in assessments?

- How would students experience this type of intervention in their learning?

This work was viewed through the framework provided by the Self-Determination Theory (SDT) of motivation, which will be discussed first. Following this, the Guided Didactic Conversation theory of distance learning and the role of gamification and play in higher education will be explored. Thereafter, detail is provided on the research methodology employed and how the intervention was implemented. After examining the results of the study, these will be discussed and recommendations for future work considered. 


\section{An Understanding of Motivation}

Although motivation is sometimes seen as a fairly stable, single-dimension characteristic that students display (Hartnett et al., 2011)-they either have it or not-others have argued that it can be changeable due to the lack of control over the many factors that influence it (Keller, 1987). Motivation is considered multidimensional in that it can vary both in level (how motivated a student is) and orientation (the "why" or type of motivation; Ryan \& Deci, 2000).

SDT is based on research examining the effect of extrinsic rewards on intrinsic motivation (Deci \& Ryan, 2012), and as gamified environments are often very reward based, SDT could provide a solid background from which to explore the motivational effects of gamification. SDT has also been recognised as a useful approach, or theoretical framework, to investigate motivation in online, distance education environments (Chen \& Jang, 2010; Hartnett et al., 2011; Simpson, 2008; Xie, Debacker, \& Ferguson, 2006) and, thus, was considered a suitable basis for this study.

SDT broadly distinguishes motivation on an intrinsic-extrinsic-amotivation continuum (Ryan \& Deci, 2000). To be intrinsically motivated is to do something because it is believed to be internally rewarding in some way, whereas extrinsic motivation has to do with tasks that lead to some external outcome such as peer approval or career advancement (Ryan \& Deci, 2000). SDT is made up of several constituent theories; relevant ones are explored here. Basic Psychological Needs Theory identifies the three universal psychological needs that form the basis of SDT (Deci \& Ryan, 2012; Robb \& Sutton, 2014; Ryan \& Deci, 2000):

- Competence (where positive feedback builds students' feelings that they are capable)

- Autonomy (the extent to which students feel that they can autonomously self-determine their actions based on an internal locus of causality)

- Relatedness (where students feel valued by others as individuals in a community context of belonging and connectedness)

All of these may be addressed in online learning environments through task submission and feedback, study flexibility, and collaborative learning via computer-mediated channels (Chen \& Jang, 2010).

Building motivation involves creating a learning environment where competence, autonomy, and relatedness are supported in order to facilitate higher levels of intrinsic motivation, ultimately leading to improved learning. Cognitive Evaluation Theory (CET; Deci \& Ryan, 2012; Ryan \& Deci, 2000) argues that it is not always possible to rely on intrinsic motivation and considers the effect extrinsic motivation has on intrinsic motivation. Any external locus of control frustrates autonomy and plays against intrinsic motivation. External, tangible rewards then undermine intrinsic motivation, as these try to enforce a particular behaviour. Furthermore, although positive feedback can build feelings of competence, this only leads to increased intrinsic motivation in autonomous environments. Similarly, social relatedness can also be autonomous or controlling, leading to either intrinsic or extrinsic motivation. Thus, where lecturer participation, feedback, and peer interaction in online courses are seen to be critical to student motivation (Xie et al., 2006), these can be understood as building confidence in a context of a supportive lecturer attitude that builds relatedness. 
However, extrinsic motivation need not always be controlling. Organismic Integration Theory (Deci \& Ryan, 2012; Ryan \& Deci, 2000) suggests a continuum of extrinsic motivation, from external regulation to integration. Extrinsic motivation is integrated when it can be internalised and is autonomous, where actions are taken freely with a sense of volition, reflecting an acceptance of the value of the task. Therefore, cultivating learning environments that show students the value of a task can lead to identification with, and integration of, the task, where the locus of causality becomes more internal and endorsed. Relatedness, in trusting and caring relationships that are responsive to others, allows a student to identify with the value of a behaviour and it becomes integrated in his/her core values. The focus, therefore, is on autonomous versus controlled motivation (Deci \& Ryan, 2012). This can be seen in studies where the controlling requirement to participate in online activities could be interpreted autonomously by students, as they identify with its value to them (Xie et al., 2006).

There are several other theories of motivation that could lead to strategies similar to SDT. The ARCS model (Attention, Relevance, Confidence, Satisfaction; Keller, 1987) picks up on sustaining attention through showing the relevance of actions in satisfying needs and accomplishing goals. Similarly, Goal Achievement Theory considers behaviour determined by performance goals that may be linked to competition with peers (Simpson, 2008). Also Self-Worth theory considers how performance can be regulated by maintaining self-worth and avoiding failure (Seifert, 2004). These may also be used to evaluate gamified approaches to learning, but will not be explored further here.

\section{Guided Didactic Conversation}

Distance education may be understood as a dialogue between lecturer and student, and this transactional approach can be seen in the teaching and learning process proposed by Holmberg (1983, 1999). Guided Didactic Conversation recommends that the communication process take on the character of an accessible conversation. This can be interpreted in two ways: firstly, there is a conversation in the form of contact via assignment questions and answers, emails, and telephone calls; secondly, it advocates a conversational style to promote feelings of a personal relationship. The argument is that building a personal relationship through conversation leads to greater personal involvement on the part of the student, and thus greater motivation to learn.

The conversation, however, is simulated, and often asynchronous (Garrison, 2000). Although originally based on paper correspondence, current technology allows for the conversion to be accomplished in a variety of forms, including audio and video podcasts, email, and virtual face-to-face meetings (Garrison, 2000; Kelsey \& D’Souza, 2004).

\section{Gamification and Play}

\section{Understanding Gamification}

Although gamification can support and enrich teaching and learning (Butgereit, 2015; Deterding, 2012), it is not uniformly understood and has no universally accepted definition or collection of elements (Bartel \& Hagel, 2016; Sailer et al., 2017). It has been defined as "the use of game design elements in non-game contexts" (Deterding, Khaled, Nacke, \& Dixon, 2011, p. 2), with the aim of tapping into the 
need for reward to increase engagement and motivate required behaviours (Deterding, 2012; Fotaris et al., 2016; Hung, 2017). Explicit use of game design and competition is engendered through the implementation of an interactive narrative context with goals, points, player levels, badges, and leader boards (Buckley \& Doyle, 2014; Butgereit, 2015; Sailer et al., 2017).

While programming and game environments have much in common-such as difficult challenges where practising strategies can build mastery (Barik, Murphy-Hill, \& Zimmermann, 2016)-it is important to distinguish gamification from other forms of games used in education (Buckley \& Doyle, 2014). In game-based learning, games are integrated in the learning context, where the content of the game is the material to be learned (Hung, 2017; Sailer et al., 2017). Gamification, however, simply provides an additional layer of rewards and reputation levels on top of the usual activities that make up a teaching and learning context (Deterding, O’Hara, Sicart, Dixon, \& Nacke, 2011).

Gamification has been used in a multitude of environments, both outside and in education (Denny, 2013; Deterding, O'Hara et al., 2011; Sailer et al., 2017; Van Roy \& Zaman, 2017). In computer programming education, it is believed that games thinking would be more understandable to computer science students (Hung, 2017), and such game-like approaches have been reported on (Barik et al., 2016; Bartel \& Hagel, 2016; Di Nunzio, Maistro, \& Zilio, 2016; Fotaris et al., 2016; Harrington, 2016; Maia \& Graeml, 2015).

The results of using gamification, however, are mixed (Hung, 2017). There are cases where positive results were noted in student behaviour, engagement, motivation, and experience (Bartel \& Hagel, 2016; Butgereit, 2015; Denny, 2013; Di Nunzio et al., 2016; Fotaris et al., 2016; Harrington, 2016) as well as in learner performance (Van Roy \& Zaman, 2017). However, there have also been cases where no significant difference was recorded in student results (Hung, 2017). It should be noted that gamification may also lead to unwanted effects and may even result in worse results than those experienced before gamification was introduced (Barik et al., 2016; Van Roy \& Zaman, 2017).

\section{Criticisms}

Gamification, however, does not enjoy universal approval and is controversial (Hung, 2017). It has been argued that it relies on the incidental parts of games that hold players' attention (Bogost, 2014; Robertson, 2010), and that it is deceitful and coercive in that it uses exploitative reward tactics to achieve required behaviours and compliance (Bogost, 2014). Hopefully, the motivation to use it in education is to benefit the student (improved marks) rather than simply make the lecturer look good (improved pass rates).

It has also been suggested that gamification takes the power of games and replaces it with exploitationware and pointsification: safe and predictable dynamics where the power and possibility of games become mere technological solutionism to promote meaningless interaction (Bogost, 2014; Hung, 2017; Robertson, 2010). Aspects of gaming that are often missing in gamified contexts are (Robertson, 2010):

- the nature of the game (interestingly difficult rather than simply a slog);

- the possibility of meaningful choices that affect what happens later in the game (rather than a required path through a set menu); and 
- emotional involvement where a player's life is at stake (where gamification rarely involves loss).

Robertson (2010) acknowledges that points and badges may be used as tools to indicate progress, but challenges the belief that it is these elements that make up the core of a game; they are used in gaming much like they are used in traditional education-to show achievement.

\section{Play}

The notion of play as an important aspect of culture and society has been highlighted by Huizinga (1970), where it acts to support something that is not play-the teaching and learning of programming, in this case. However, a playful approach can embody some of the characteristics of play, as highlighted by Huizinga (1970):

- It is a voluntary activity where learners choose whether they want to participate or not.

- Play is not real life, but a fun activity. In a sense, then, the learning of programming is the reallife context, whereas the gamified layer on top of this forms the playful part.

- Play takes place in a playground with limits to its time and place. Again, a gamified context is limited to the reward layer of the learning environment.

- Play has rules, which are embodied in the points offered in a gamified approach, where the points, and their associated badges and levels, are awarded for completing specific tasks.

- Play has a differentness expressed in the uniforms worn by players. Avatars and game-names combine to display this differentness and to disguise the individual (who becomes someone else, in a sense).

Students, then, play the game of learning programming, while the gamified approach adds a playful process to that learning. The approach used here is characterised as playful rather than gamified in recognition of the criticisms of the term "gamification," and fun is used as a dynamic rather than an attempt to turn the course into an actual game.

\section{Methodology and Implementation}

\section{Research Design and Methods}

The research design used in this study was action research, with two cycles reported here and suggestions from the evaluation for alterations that could be made leading to further cycles. The underlying philosophy of action research is pragmatism, where action should lead to practical consequences (Baskerville \& Myers, 2004), which, in this specific case, would be motivating distance students to participate more actively in the programming course and with its learning content. This pragmatist grounding provides action research with its focus on finding truth in practical outcomes, with reason and action together leading to change, change that occurs as human social interaction shapes action (Adams, 2010; Baskerville \& Myers, 2004). 
Action research has social change as one of its primary goals (Adams, 2010). It is a longitudinal, iterative, and continuous approach that cycles through phases of planning, acting, observing, and reflecting, making it more of a process of learning for, in, and from practice than a single event (Adams, 2010; De Villiers, 2005). The role of the researcher is that of practitioner-researcher, where a lecturer examines his/her own practice, and is, thus, very responsive to data collected and flexible in reactions to findings from the observations (De Villiers, 2005). This close relationship to the research means that any interpretations may be limited (Adams, 2010) and that the researcher has to be very aware of his/her own values around what constitutes learning and what he/she believes a student should be doing.

A multi-method approach to data collection was used:

- Statistics relating to the number of interactions on the learner management system, as well as the number of assignments submitted, were collected for all students for the time period of 2014 to 2017.

- Students for the two semesters in 2016 (S1 and S2) and one in 2017 (S2), when the approach was used, were surveyed using Likert-type scales, multiple-choice options, and freeform responses near the end of each semester. Questions related to student demographics, and response to, and participation in, the gamified approach. Participants included all the students registered for the course during the semester (except where students asked to be excluded from the intervention). Of those who responded, the majority were male (78\%), with ages ranging from 21 to 51 years of age (the average being 31), and mostly registered for the Bachelor of Science in Computing programme (73\%). No other demographics concerning the participants is known.

Ethical clearance was obtained from the appropriate university committees, both to do the research and to use university data.

\section{Learning Intervention}

In an attempt to motivate students and increase engagement with a programming course, it was decided to introduce a fun or playful element in the course. The context was a third-year programming course required for a major in computer science offered only via a distance education online mode. It is not proposed here to turn programming into a game, but to use playful elements to engender motivation. Participation was measured by considering the number of students who introduced themselves online and their comments to other students, the number of students who submitted each of the two set assignments (where just one assignment was required to gain examination admission), and the marks obtained for those assignment tasks. The approach was implemented in two semesters in 2016 (Cycle 1) and the second semester in 2017 (Cycle 2).

Eight game mechanics were included in the approach:

- A journey motif provided the overarching story, involving a destination or goal, tasks that needed to be completed along the way, and a means of measuring progress.

- Students provided known-as names and introduced themselves in an on-boarding process. 
- Set tasks (the two semester assignments) provided short-term goals.

- Points were awarded for completing tasks: submitting known-as names, participating in the introductions, taking part in quick quizzes, and submitting assignments. Assignment points were awarded based on the mark achieved for the assignment.

- Badges were issued for completing tasks (such as a Greeters badge for introducing oneself in the online discussion forums) and for indicating levels of progress (such as three different assignment badges based on the assignment mark achieved in each assignment). Thus, badges were awarded both for performance and competence (Van Roy \& Zaman, 2017).

- A leader board was maintained, and student rankings were sent out after major tasks along the journey.

- Four levels (reached on gaining a set number of points) were used to provide intermediate goals: Roamer, Rambler, Rover, and Ranger. Badges were also associated with each of these levels.

- Individual and group feedback loops were provided via email on a regular basis. Badges, points, and rank status messages were sent to individual students; summary messages (such as the number of students at each level) were sent to all students via the university learner management system.

The differences in game-mechanic implementation from Cycle 1 to Cycle 2 were as follows:

- A journey-specific website was added in Cycle 2. This website was used to indicate progress such as how many badges of each type had been issued.

- The leader board was kept private in Cycle 1, and although students received emails indicating their rank, they could not see where others were placed. A public leader board was introduced in Cycle 2 and was published on the journey website. The student-provided "known as" names were used where available; otherwise, anonymised student numbers were used.

- Motivational emails were sent to students in Cycle 2. These were sent out at set points throughout the semester after significant points in the journey (such as the release of the assignment marks and solutions). This game mechanic was implemented following a similar strategy used in another distance learning environment (Keller, 1999).

\section{Results}

\section{Behaviour Change}

There was little evidence that the gamified interventions led to much behaviour change or improved scores (see

Table 1). 
Table 1

Course Statistics for Students Registered for the Programming Course

\begin{tabular}{|c|c|c|c|c|c|c|c|c|}
\hline & $\begin{array}{c}2014 \\
\mathrm{~S} 1\end{array}$ & $\begin{array}{c}2014 \\
\mathrm{~S} 2\end{array}$ & $\begin{array}{c}2015 \\
\text { S1 }\end{array}$ & $\begin{array}{l}2015 \\
\mathrm{~S} 2\end{array}$ & $\begin{array}{c}2016 \\
\text { S1 }\end{array}$ & $\begin{array}{c}2016 \\
\mathrm{~S} 2 \\
\end{array}$ & $\begin{array}{c}2017 \\
\text { S1 }\end{array}$ & $\begin{array}{c}2017 \\
\mathrm{~S} 2\end{array}$ \\
\hline Action research cycles & & & & & $\begin{array}{c}\text { Cycle } \\
1\end{array}$ & $\begin{array}{c}\text { Cycle } \\
1\end{array}$ & & $\begin{array}{l}\text { Cycle } \\
2\end{array}$ \\
\hline Number of introductions & & & 78 & 53 & 112 & 157 & & 122 \\
\hline \% of "known as" names & & & & & 34 & 31 & & 19 \\
\hline $\begin{array}{l}\text { \% of Assignment 1s } \\
\text { submitted }\end{array}$ & 86 & 90 & 91 & 89 & 91 & 91 & 89 & 98 \\
\hline $\begin{array}{l}\text { \% of Assignment 2s } \\
\text { submitted }\end{array}$ & 53 & 58 & 58 & 58 & 50 & 61 & 63 & 67 \\
\hline Average \% for Assignment 1 & 43 & 52 & 43 & 49 & 45 & 55 & 60 & 44 \\
\hline Average \% for Assignment 2 & 49 & 51 & 46 & 42 & 53 & 55 & 69 & 50 \\
\hline Examination pass rate & 41 & 56 & 47 & 42 & 43 & 42 & 42 & 44 \\
\hline Examination average \% & 45 & 47 & 48 & 44 & 45 & 44 & 40 & 46 \\
\hline
\end{tabular}

Although the number of online introduction interactions doubled, few students sent in names to be known as on the journey, with the numbers decreasing since the first intervention. It should be noted that the low number in $2017 \mathrm{~S} 2$ could have been as a result of students not expecting the gamified approach to be continued in the semester after it had not been used in S1.

It was also clear that there had been little effect on the percentage of assignments submitted during the first action research cycle in $2016 \mathrm{~S} 1$ and S2, although there did seem to have been an increase in the second cycle (2017 S2). Similarly, the average marks for the assignments changed little from before the interventions were implemented, as did the examination pass rates and examination averages. It is noteworthy that higher than average results were obtained in $2017 \mathrm{~S} 1$ assignments when there was no journey approach, indicating that there were other factors at play there.

\section{Student Perceptions}

Student perceptions of the approach, based on 30 survey responses from the first action research cycle (a 9\% response rate) and 37 from the second (a 22\% response rate), were very positive. Of those who responded to the survey, $84 \%$ enjoyed the approach, with the remainder having no opinion (see Table 2). Also, when asked about how their attitudes towards the journey had changed from start to end, five respondents' opinions moved in a negative direction, with 10 remaining neutral; the rest either were, or became, positive towards the approach (see

Table 3). Note that no respondents changed from positive to negative or from negative to neutral.

Table 2

Overall Response to the Playful Approach Adopted in the Course

\begin{tabular}{ccccccc}
\hline Cycle & $\begin{array}{c}\text { Number of } \\
\text { students }\end{array}$ & I loved it & I liked it & I really have no opinion & I did not like it & I hated it \\
\hline Cycle 1 & 30 & 11 & 15 & 4 & 0 & 0 \\
\hline Cycle 2 & 37 & 10 & 20 & 7 & 0 & 0 \\
\hline
\end{tabular}


Table 3

Attitude Change Towards the Playful Approach Adopted in the Course

\begin{tabular}{lcccccc}
\hline Cycle & $\begin{array}{c}\text { Number of } \\
\text { students }\end{array}$ & $\begin{array}{c}\text { Positive to } \\
\text { neutral }\end{array}$ & $\begin{array}{c}\text { Negative to } \\
\text { positive }\end{array}$ & $\begin{array}{c}\text { Remained } \\
\text { neutral }\end{array}$ & $\begin{array}{c}\text { Neutral to } \\
\text { positive }\end{array}$ & $\begin{array}{c}\text { Remained } \\
\text { positive }\end{array}$ \\
\hline Cycle 1 & 30 & 1 & 2 & 4 & 13 & 10 \\
\hline Cycle 2 & 37 & 4 & 1 & 6 & 15 & 10 \\
\hline
\end{tabular}

The respondents also largely agreed that they had actively participated in the journey, that it had helped maintain their motivation, and that it had led to positive behaviour changes (see Table 4). It must be acknowledged that the respondents mostly came from students who had progressed far along the journey, where 50\% had reached the two highest levels (Rover and Ranger; see Table 5).

Table 4

Student Response to the Use of the Playful Approach

\begin{tabular}{lcccccc}
\hline Choice & Cycle & $\begin{array}{c}\text { Strongly } \\
\text { agree }\end{array}$ & Agree & Neutral Disagree & $\begin{array}{c}\text { Strongly } \\
\text { disagree }\end{array}$ \\
\hline I actively participated in the journey & Cycle 1 & 8 & 12 & 8 & 1 & 1 \\
\cline { 2 - 7 } The journey helped maintain motivation & Cycle 2 & 2 & 13 & 14 & 4 & 4 \\
\cline { 2 - 7 } & Cycle 1 & 9 & 11 & 6 & 2 & 2 \\
\hline $\begin{array}{l}\text { The journey led to a positive behaviour } \\
\text { change }\end{array}$ & Cycle 1 & 4 & 17 & 6 & 4 & 6 \\
\cline { 2 - 7 } & Cycle 2 & 5 & 17 & 7 & 2 & 6 \\
\hline
\end{tabular}

Table 5

Levels Reached by Students Participating in the Survey

\begin{tabular}{lccccccc}
\hline Cycle & Number of students & Roamer & Rambler & Rover & Ranger & I do not care & I do not know \\
\hline Cycle 1 & 30 & 4 & 4 & 7 & 14 & 1 & 0 \\
\hline Cycle 2 & 35 & 8 & 9 & 7 & 6 & 0 & 5 \\
\hline
\end{tabular}

A thematic analysis of the free-form responses identified the following themes, which could be separated into positive and negative categories. Actual responses from students are indicated by participant numbers in this reporting. Five positive themes were noted:

1. Confidence in making progress: students noted that "It shows my progress" [P6] and that it was "good for me to see how I stack up against other students" [P14], leading to comments that it "gave me confidence" [P13] and "a sense of accomplishment" [P17]. Furthermore, it provided a "[s]ense of direction" [P35].

2. Motivation: students felt that the approach "motivated me to study harder" $\left[\mathrm{P}_{7}\right]$ through "keep[ing] you involved" [P33] and "had a small goal to work towards" [P38]; it "acted as a motivator" [P10]. It was noted that "competitiveness motivates" [P49]. 
3. Competition: some students noted that they "liked seeing where I was ranked in the class" [P4], and in the first cycle, requests were made for the leader board to be made public. There was also the request for more ways to earn points, such as more quick quizzes.

4. Being connected: a common thread was that the approach "makes the experience more personal" [P8], where "the lecturer ... is actively involved" [P16], "available" [P41], and "hands on" [P32]. There was also the feeling that the approach helped students feel connected to other students.

5. Unique approach: students often found the journey "innovative" [Р39], "different but quite exciting" [P9], "fun and engaging" [P10], and "encouraging" [P58]. There were even comments that "all modules would greatly benefit from having this approach" [P4].

However, four negative themes also emerged:

1. Added expectations: there was the feeling that the journey "put a bit more pressure on me" $[\mathrm{P} 16]$ and that there was now extra "pressure to fulfil all the requirements" $[\mathrm{P} 12]$ because "more was expected of me" [P16] over and above what already had to be done to fulfil the requirements of the course.

2. Disappointment and discouragement: students felt that "I could of done better" [P24] and were "disappointed in myself for not allocating sufficient time to complete assignment 2" [P16]. There was also the realisation that "I would have been discouraged if I had obtained a low rank" [P17].

3. Time pressures: the extra pressure that was felt led to students indicating that "I did not have the time to be involved in it" [ $\left.\mathrm{P}_{5}\right]$ and that the "journey work load was too much for me" [P64], and so they did not actively participate.

4. Indifference: one student noted that "I think people don't really care" [P31], indicating some indifference to whether this approach was taken or not.

\section{Discussion and Future Work}

A playful or gamified approach to presenting a computer programming course in a distance education environment needs to support the three basic psychological needs proposed by SDT rather than be a narrow points-badges-leader board approach (Van Roy \& Zaman, 2017). Such reduced-complexity approaches may well fail to engage students (Deterding, 2012). It must be acknowledged that the journey storyline may have been too weak to act as an overriding purpose for completing tasks, in that it did not relate directly to the programming tasks and remained an unintegrated layer on top of the usual programming tasks required in the course.

The awarding of points and badges for successful assignment submissions can help build feelings of competency in students. In a sense, then, the points, badges, and levels act as supportive feedback indicating a student's progress as well as adding a sense of "guided conversation." However, the immediacy of this feedback can be problematic. Although immediate feedback is achievable for small 
self-assessment-type tasks where automatic feedback can be provided in an LMS, it remains a problem for the larger programming assignments that can take several weeks to finish marking. It is possible that it was this need for rapid feedback (as well as more ways to earn points and progress to the next level) that led to students requesting more quick quizzes. However, wanting more tasks could also represent the need for more dialogue with the lecturer. Furthermore, there was the assumption that distance students, who might additionally be part-time students, had the time to devote to their studies as well as the time to participate in the journey. It could be such a lack of time that contributed to demotivated students (Xie et al., 2006), and motivation to continue with the journey may also be lost if students do not do well in assignments and so fall behind on the leader board, leading to loss of interest in the journey (Fotaris et al., 2016).

To maintain the autonomy of students and the flexibility of the journey, it was decided not to make participation in the journey compulsory and, thus, to try to build a less controlling form of motivation through voluntary participation. This was also done to recognise that not only were not all students motivated by a ranking on a leader board (Bartel \& Hagel, 2016), but that it was possible that being ranked against peers might demotivate some students (Abu-Dawood, 2016; Buckley \& Doyle, 2014). Furthermore, the student also maintained the choice of name by which he/she was known, adding to the sense of autonomy (Sailer et al., 2017). It needs to be noted, however, that beyond this, there were little flexibility and a lack of options as far as the journey itself was concerned: the set assignments were compulsory, and there were no options providing alternative pathways through the course. It is, thus, possible that such lack of provided autonomy may demotivate students and lead to the indifference that was noted.

Feelings of relatedness were built through the on-boarding process of having a known-as name and introducing oneself on the discussion forums, where there might be a realisation that the student was not alone in this learning journey. Establishing such an identity also supported the second stage of the five-stage model for online teaching and learning (Salmon, Nie, \& Edirisingha, 2010). Furthermore, regular emails sending out badges and updating students on their points and rank status supported the need for relatedness and dialogue, as did a public website where students could see that others were on this journey, too. While interaction may be supportive of success in distance education courses (Kelsey \& D'Souza, 2004), it is a myth that more interaction leads to better learning (Simonson et al., 2012). Research has indicated that students welcome contact specifically with their lecturers (Kelsey \& D'Souza, 2004), a view that was supported by the appreciation shown by students of the journey in this study.

A gamified approach involves a lot of effort, and it is necessary to ask whether it is worth this effort, especially as success is not guaranteed (Bartel \& Hagel, 2016). Considering the positive effect that it had on student experience and that some students felt motivated and encouraged by the journey, one cannot deny that it may have a place among all the other interventions that are implemented in such courses in an attempt to meet the learning needs of a range of different students (Buckley \& Doyle, 2014). However, it is probably not the form of gamified approach to be taken if the aim is to improve marks and pass rates. This would be in keeping with the arguments made by the authors upholding the "no significant difference" phenomenon - that there are too many variables that lead to success in education and that one intervention is unlikely to lead to any significant difference in student achievement (Conger, 2005). 
This work could be extended in further cycles of action research by considering options for redeeming points and the use of avatars in addition to journey names. Extra ways of earning points could be added through the addition of more self-assessment tasks and even the inclusion of examination marks (as this is the only part of evaluation in the course that was not included). To encourage student-student engagement, points could also be awarded for contributing to discussions on the discussion forum (Harrington, 2016). A larger task would be to consider changing the programming assignments to match the journey theme. The approach is also limited in that it could not be integrated into the university's learning management system, and it would be worth exploring whether this would increase participation.

\section{Conclusion}

Aiming to build motivation among distance education students to engage with the content of a programming course, a more playful approach was introduced to the process of undertaking the course. Such approaches do accord with theories of motivation and of distance learning: they endeavour to engage the student in a dialogue with the course material and lecturer, seeking to give the student some confidence and limited autonomy in achieving goals together with their peers. However, such approaches are unlikely to be the panacea some may hope them to be (Deterding, 2012). Furthermore, they are not mature educational practices yet and it might be too early to write off their potential (Hung, 2017). Consequently, more work needs to be done to explore their value in higher education.

This study argues that the use of game elements in a playful approach to a programming course may have positive motivational effects. Even though it may not lead to increased participation in coursework, it does have very positive effects on student perception, appreciation, and experience of such a distance learning course. Where the aims are to provide a student who may have no other options to access higher education with a valuable learning experience, to counter some of the isolation problems experienced by such distance education students, and to provide the student with a sense of a caring lecturer, this approach may be worth considering. 


\section{References}

Abu-Dawood, S. (2016). The cognitive and social motivational affordances of gamification in e-learning environment. In Proceedings of the IEEE 16th International Conference on Advanced Learning Technologies, ICALT 2016 (pp. 373-375). http://doi.org/10.1109/ICALT.2016.126

Adams, P. (2010). Action research. In Encyclopedia of Research Design (pp. 5-10). http://doi.org/10.4135/9781412961288.n3

Barik, T., Murphy-Hill, E., \& Zimmermann, T. (2016). A perspective on blending programming environments and games: Beyond points, badges, and leaderboards. In Proceedings of the IEEE Symposium on Visual Languages and Human-Centric Computing, VL/HCC (pp. 134142). http://doi.org/10.1109/VLHCC.2016.7739676

Bartel, A., \& Hagel, G. (2016). Gamifying the learning of design patterns in software engineering education. In Proceedings of the 2016 Global Engineering Education Conference (EDUCON) (pp. 74-79). Abu Dhabi, UAE. http://doi.org/10.1109/EDUCON.2016.7474534

Baskerville, R. L., \& Myers, M. D. (2004). Special issue on action research in information systems: Making IS research relevant to practice- Foreword. MIS Quarterly, 28(3), 329-335.

Bogost, I. (2014). Why gamification is bullshit. In S. P. Walz \& S. Deterding (Eds.), The gameful world: Approaches, issues, applications (pp. 65-79). Cambridge, MA: The MIT Press.

Buckley, P., \& Doyle, E. (2014). Gamification and student motivation. Interactive Learning Environments, 24(6), 1162-1175. http://doi.org/10.1080/10494820.2014.964263

Butgereit, L. (2015). An experiment in using gamification in an information technology distance classroom. In Proceedings of the 44th Conference of the Southern African Computer Lecturers' Association (SACLA) (pp. 69-76). Johannesburg.

Butler, S., \& Ahmed, D. T. (2016). Gamification to engage and motivate students to achieve computer science learning goals. In Proceedings of the 2016 International Conference on Computational Science and Computational Intelligence (pp. 237-240). Las Vegas, USA: IEEE. http://doi.org/10.1109/CSCI.2016.52

Chen, K. C., \& Jang, S. J. (2010). Motivation in online learning: Testing a model of self-determination theory. Computers in Human Behavior, 26(4), 741-752. http://doi.org/10.1016/j.chb.2010.01.011

Conger, S. B. (2005). If there is no significant difference, why should we care? The Journal of Educators Online, 2(2), 1-4.

De Villiers, M. R. (2005). Three approaches as pillars for interpretive Information Systems research: Development research, action research and grounded theory. In Proceedings of the 2005 Annual Research Conference of SAICSIT on IT Research in Developing Countries (pp. 142151). 
Deci, E. L., \& Ryan, R. M. (2012). Self-determination theory. In P. A. M. van Lange, A. W. K. Higgins, \& E. T. Higgins (Eds.), Handbook of theories of social psychology (Vol. 1; pp. 416-437). London: Sage Publications. http://doi.org/10.4135/9781446249215.n21

Denny, P. (2013). The effect of virtual achievements on student engagement. In Proceedings of the SIGCHI Conference on Human Factors in Computing Systems (CHI '13pp. 763-772). Paris, France. http://doi.org/10.1145/2470654.2470763

Deterding, S. (2012). Gamification: Designing for motivation. ACM Interactions, 19(4), 14-17. http://doi.org/10.1145/2212877.2212883

Deterding, S., Khaled, R., Nacke, L., \& Dixon, D. (2011). Gamification: Toward a definition. In Proceedings of the ACM CHI Conference on Human Factors in Computing Systems Gamification workshop (pp. 1-4). Vancouver, Canada. Retrieved from http://gamificationresearch.org/wp-content/uploads/2011/04/o2-Deterding-Khaled-Nacke-Dixon.pdf

Deterding, S., O’Hara, K., Sicart, M., Dixon, D., \& Nacke, L. (2011). Gamification: Using game design elements in non-game contexts. In Proceedings of the 2011 Annual Conference on Human Factors in Computing Systems (CHI 2011; pp. 2425-2428). Vancouver, BC, Canada. http://doi.org/10.1145/1979742.1979575

Di Nunzio, G. M., Maistro, M., \& Zilio, D. (2016). Gamification for machine learning: The classification game. In Proceedings of the Third International Workshop on Gamification for Information Retrieval (pp. 45-52). Pisa, Italy.

Fotaris, P., Mastoras, T., Leinfellner, R., \& Rosunally, Y. (2016). Climbing up the leaderboard: An empirical study of applying gamification techniques to a computer programming class. The Electronic Journal of E-Learning, 14(2), 94-110.

Garrison, R. (2000). Theoretical challenges for distance education in the 21st century: A shift from structural to transactional issues. The International Review of Research in Open and Distributed Learning, 1(1), 1-8.

Harrington, B. (2016). TrAcademic. In Proceedings of the 21st Western Canadian Conference on Computing Education (WCCCE '16; pp. 25:1-25:2). Kamloops, BC, Canada: ACM. http://doi.org/10.1145/2910925.2910932

Hartnett, M., St George, A., \& Dron, J. (2011). Examining motivation in online distance learning environments: Complex, multifaceted, and situation-dependent. The International Review of Research in Open and Distributed Learning, 12(6), 20-38.

Holmberg, B. (1983). Guided didactic conversation in distance education. In David Sewart, D. Keegan, \& B. Holmberg (Eds.), Distance education: International perspectives (pp. 114-122). London: Croom Helm.

Holmberg, B. (1999). The conversational approach to distance education. Open Learning, 14(3), 586o. http://doi.org/10.1080/0268051990140309 
Huizinga, J. (1970). Homo ludens. London: Temple Smith.

Hung, A. C. Y. (2017). A critique and defense of gamification. Journal of Interactive Online Learning, $15(1), 57-72$.

Keller, J. M. (1987). Development and use of the ARCS model of instructional design. Journal of Instructional Design, 1O(3), 2-10. http://doi.org/10.1007/978-1-4419-1250-3_3

Keller, J. M. (1999). Using the ARCS motivational process in computer-based instruction and distance education. New Directions for Teaching and Learning, 78, 39-47. http://doi.org/10.1002/tl.7804

Kelsey, K. D., \& D’Souza, A. (2004). Student motivation for learning at a distance: Does interaction matter? Online Journal of Distance Learning Administration, 7(2), 1-10.

Maia, R. F., \& Graeml, F. R. (2015). Playing and learning with gamification: An in-class concurrent and distributed programming activity. In Frontiers in Education Conference (FIE) (pp. 1-6). El Paso, Texas: IEEE. http://doi.org/10.1109/FIE.2015.7344135

Pineda-Corcho, A. F., \& Moreno-Cadavid, J. (2017). Proposal of a gamified virtual learning environment for computer programming courses. In Proceedings of the 2017 IEEE Global Engineering Education Conference (EDUCON) (pp. 1671-1675). Athens, Greece.

Robb, C. A., \& Sutton, J. (2014). The importance of social presence and motivation in distance learning. The Journal of Technology, Management, and Applied Engineering, 31(2), 2-10.

Robertson, M. (2010). Can't play, won't play. Retrieved from http://www.hideandseek.net/2010/10/06/cant-play-wont-play

Ryan, R. M., \& Deci, E. L. (2000). Intrinsic and extrinsic motivations: Classic definitions and new directions. Contemporary Educational Psychology, 25, 54-67. http://doi.org/10.1006/ceps.1999.1020

Sailer, M., Hense, J. U., Mayr, S. K., \& Mandl, H. (2017). How gamification motivates: An experimental study of the effects of specific game design elements on psychological need satisfaction. Computers in Human Behavior, 69, 371-380. http://doi.org/10.1016/j.chb.2016.12.033

Salmon, G., Nie, M., \& Edirisingha, P. (2010). Developing a five-stage model of learning in Second Life. Educational Research, 52(2), 169-182. http://doi.org/10.1080/00131881.2010.482744

Seifert, T. (2004). Understanding student motivation. Educational Research, 46(2), 137-149. http://doi.org/10.1080/0013188042000222421

Simonson, M., Smaldino, S., Albright, M., \& Zvacek, S. (2012). Teaching and Learning at a distance (5th ed.). Boston, MA: Pearson.

Simpson, O. (2008). Motivating learners in open and distance learning: Do we need a new theory of learner support? Open Learning: The Journal of Open, Distance and E-Learning, 23(3), 159- 
170. http://doi.org/10.1080/02680510802419979

Simpson, O. (2012). Supporting students for success in online and distance education (3rd ed.). New York, NY: Routledge.

Van Roy, R., \& Zaman, B. (2017). Why gamification fails in education - and how to make it successful. In M. Ma \& A. Oikonomou (Eds.), Serious Games and edutainment applications (Vol. II; pp. 485-509). Chan, Switzerland: Springer International Publishing AG. http://doi.org/10.1007/978-3-319-51645-5_22

Xie, K., Debacker, T. K., \& Ferguson, C. (2006). Extending the traditional classroom through online discussion: The role of student motivation. Journal of Educational Computing Research, 34(1), 67-89. http://doi.org/10.2190/7BAK-EGAH-3MH1-K7C6

\section{Athabasca \\ University}

(2) $\stackrel{\odot}{-1}$ 